Perera P.A.L.P. and De Silva, N., 2021. A model to assess the maintenance leanness of apparel industry buildings in Sri Lanka. In: Sandanayake, Y.G., Gunatilake, S. and Waidyasekara, K.G.A.S. (eds). Proceedings of the $9^{\text {th }}$ World Construction Symposium, 9-10 July 2021, Sri Lanka. [Online]. pp. 27-38. DOI: https://doi.org/10.31705/WCS.2021.3. Available from: https://ciobwcs.com/papers/

\title{
A MODEL TO ASSESS THE MAINTENANCE LEANNESS OF APPAREL INDUSTRY BUILDINGS IN SRI LANKA
}

\author{
P.A.L.P. Perera ${ }^{1}$ and Nayanthara De Silva ${ }^{2}$
}

\begin{abstract}
Escalating needs of availability in built environments have pursued maintenance to be recognized with the strategic importance notwithstanding the conventional belief of necessary evil. Nevertheless, it absorbs the three-quarters of whole building lifecycle cost. Studies proved that proportion significantly contributed by inefficiencies owing to poor maintenance, lack of reliability focus, poor management commitment, technical and human resources-related issues. Consequently, Sri Lankan buildings opted to adopt numerous strategic management approaches such as Lean, Six-Sigma to acquire the higher status of efficiency and effectiveness in their operations. Simultaneously, adherence to lean concepts was apparent in Sri Lankan manufacturing context, relatively fewer attempts were made on establishing assessment procedures to distinguish the degree of leanness. Hence, research was focused on developing an assessment model to address the leanness levels in maintenance operations. Lean quantification metric "Leanness" in maintenance is defined through identified parameters in literature and those were narrowed down into seven (7) leanness criteria and further expanded into forty-two (42) leanness attributes paving a pathway to the formation of a theoretical assessment model. For the investigation, nine semi-structured interviews were conducted from three identical cases. The derived data were analysed using the manual content analysis technique. Empirical findings revealed satisfactory adherence scoring the thirty-eight (38) attributes accomplishment as the highest and twenty-five (25) as the least. Findings point out significant gaps in lack incorporation of planned maintenance programs with maintenance inventory-related aspects, lack of undertakings on extensive reliability analysis efforts for maintenance activities. The outcomes will mark valuable insights for building practitioners to engage in maintenance operations in a versatile manner to acquire a waste-free, quality, stakeholder-driven maintenance environment.
\end{abstract}

Keywords: Built environment; Lean maintenance (LM); Leanness; Leanness assessment; Sri Lanka.

\section{INTRODUCTION}

In recent decades, building maintenance was given the utmost importance worldwide due to the increasing complexities of built environments. Henceforth, it is a disciplinary, closely related to essential routines that ensure the desired performance outcomes of the building, safety, and the quality of the occupants' lives (Chan et al., 2009). It touches the broad scope and is associated with a costly process in terms of both financial and

\footnotetext{
${ }^{1}$ Department of Building Economics, University of Moratuwa, Sri Lanka, lahiruni992@gmail.com

${ }^{2}$ Department of Building Economics, University of Moratuwa, Sri Lanka, endds@uom.lk
} 
environmental dimensions (Puķite and Geipele, 2017). Quantitatively, the operating cost of the buildings is contributed by to $75-80 \%$ of built-asset operation and the maintenance cost (Madureira et al., 2017). Moreover, $30 \%$ of additional energy consumed by building equipment and components that are not adequately maintained and operated and leading to frequent equipment downtime (Kim and Katipamula, 2018). Thus, high expenses occurred due to the insufficient reliability of systems and created many declines in the service delivery (Salata et al., 2014). Lack of management commitment, technical and human resources-related issues, lack of integration with organizational objectives, lack of spare parts, incapability to cope up with the modern technology increased inefficiencies generating the "waste" in the building maintenance function (Ali et al., 2016; Lateef et al., 2010). To curtail those deadly wastes and effectively assist the operations of the organization while diluting the pressure put on maintenance, a systematic approach has gained a significant focus (Lahiri et al., 2008). Driven by that intention, most of the organizations embraced the concept of lean, the multi-dimensional approach that aims at eliminating "waste", (Muda in Japanese) while enhancing the value of the operations (Womack and Jones, 2003). Researchers interpreted it as a journey, which requires continuous monitoring to assess the existing levels of leanness and direct into the potential improvements (Narayanamurthy and Gurumurthy, 2016). Among the main components of the lean implementation cycle: Lean training, Value Stream Mapping (VSM), and Lean Assessment, Lean Assessment generate more information (Wan and Chen, 2009) recognizing the problematic areas to be improved (Alemi and Akram, 2013; Urban, 2015). Notwithstanding the fact, few researchers have attempted on investigating the "leanness" aspects of maintenance environments (Narayanamurthy and Gurumurthy, 2016). Gupta et al. (2019) derived the Lean Maintenance Index (LMI) via the incident matrix approach focusing on the key features of LM. Moving to the Sri Lankan manufacturing environment, adherence to the lean application, Total Productive Maintenance (TPM), evident, but its effect has not adequately assessed by researchers (Wickramasinghe and Perera,2016). Fulfilling that gap, the study aims at formulating a leanness assessment model to assess the degree of "leanness" that prevails in the building maintenance domain. Concurrently, the study will extract the potentials of embedding the "fine-tuned" TPM practices: i.e., Lean Maintenance (LM) theories providing valuable insights for building practitioners to achieve a waste-free, quality, stakeholder-driven maintenance environment (Wan and Chen, 2009).

\section{LITERATURE REVIEW}

Following subsections denotes the key literature findings regarding research focus which ultimately leads to the formulation of the model to assess the leanness in building maintenance.

\subsection{THE CONCEPT OF LEAN AND LEAN MAINTENANCE}

The versatile concept, "Lean" was first coined in the book "The machine that changed the world: story of lean production" resulting in the massive production environments that are highly responsive to the changes in customer demand (Poppendieck, 2002). Lean thinking can be defined as a capability to provide the exact product output that the customer requires at a reasonable price and minimal time consumption while optimally conserving the system inputs (transformed resources and transforming resources) (Shou et al., 2019 ; Thürer et al., 2016). The concept of "waste" which is highly termed with 
Lean has been evolved from the cost and waste reduction perception to enhance customer satisfaction. Recent literature added the eight-waste component: underutilized employee creativity to the "classical seven wastes" of "overproduction, waiting, transportation, process waste, inventory, waste motion, and defects" (Mostafa et al., 2015; Liker, 2003). Followed by the hypothesis developed by Womack and Jones (2003) on its universal application, many researchers have attempted to integrate the lean principles to maintenance comprehensively mapping the aforesaid wastage and overseeing it as a pathway to obtain the reliable, cost-effective maintenance status (Abreu et al., 2016 ;Verma and Ghadmode , 2004). Accordingly, the concept of LM practices took its lead injecting the new principles to TPM constructing the clear structural pathway with longterm strategic perspective away from the business dynamics (Baluch et al., 2012; Clarke et al., 2010). Smith and Hawkins (2004) broadly defined the LM as a "Proactive maintenance operation employing the planned and scheduled maintenance activities through TPM practices, using maintenance strategies developed through application of $\mathrm{RCM}$ decision logic and practiced by empowered (self-directed) using the $5 \mathrm{~S}$ process, weekly kaizen improvements autonomous maintenance (AM) using the maintenance work order system, Computerized Maintenance Management System (CMMS), Enterprise Asset Management system (EAS)” (p. 257).

\subsection{LeAnNeSS ASSESSMENT MethodS}

Leanness is a useful metric that is used to quantify the level of lean implementation and its progress, or the potential achievements in the future (Alemi and Akram, 2013). According to Hallam (2003) "Lean quantification" or the "Leanness Assessment" defined as a procedure which supports to evaluate the level of "leanness" accomplished either qualitative or quantitative terms and inherent with certain key characteristics: quantifiable and adheres to the strategic objectives of the organization and customer values, capability to dominate and evaluate the performance, supports to realize the current state and potential opportunities for further improvements and contemporary (repetitive evaluation) and realistic. Assessments based on performance and the adoption of practices are the widely used main approaches of leanness assessment (Cocca et al., 2019; Singh et al., 2010). Practice-based assessments act as a tool to guide the success of their implementations, track the potential improvements whereas a performance-based approach focus on improving the level of achievement in the performance outcomes caused by lean adoption (Urban, 2015). Moreover, existing literature needs conducting more research on lean assessment frameworks or instruments due to the lack of presence in literature and its flexibility to extend for the different sectors to fit with the dynamic changes (Narayanamurthy and Gurumurthy, 2016). Fulfilling that gap of relatively fewer efforts in this context, the study aims at developing the practice-based lean assessment model which has the flexibility of extending for numerous sectors. Accordingly, the relevant literature derived through digital keyword search "Lean Maintenance", "Lean Thinking Maintenance" during the period of 2001-2020 were synthesized and parameters for the assessment were identified accordingly. Thus, Maintenance Leanness can be defined as follows.

The measure that aims to integrate Lean tools and techniques, to enhance the maintenance effectiveness, maintenance cost utilization, and maintenance quality through the optimized maintenance planning and scheduling, resource utilization, equipment management, Maintenance automation, effective problem diagnosis, effective utilization of the maintenance data, continuous improvement efforts while managing the workforce 
to cater the business needs under involvement of positive management which ensures the secured workplace and smooth informational flow.

All parameters were presented under the seven "leanness criteria" and those were expanded into 42 "leanness attributes" (Table 1).

Table 1: Leanness attributes

$\begin{array}{ll}\text { LCanness } & \text { Leanness Attributes } \\ \text { attributes } & \\ \text { LC1.2 - Smooth informational flow via a powerful communication network } \\ \text { LC1.3 - Visual displays of safety, quality, cost, delivery, and productivity data to the } \\ \text { employees }\end{array}$

LC4.1 - Establish Autonomous Maintenance standards.

LC4.2 - Machine operators were given an overview of the machine, how to perform the inspections of the basic operations of the machines

LC4.3.-Visual standards regarding cleaning, lubrication, tightening and loosening and
tightening through immediate feedback about the current standards of affairs
LC4.4 - PM activities are taken place to prevent the occurrence of the breakdowns
LC4.5.- PM aligned with the provision of work procedures, documents, or tools including
the detailed information regarding the safety requirements

LC4.6 - Data utilization to come up with effective decision making

LC4.7-Systematic diagnosis of losses and failures and track and address the equipment problems and root causes setting 3M (Material, Man, and machine) conditions

LC4.8 - Development Management via continual evaluation and improvement of the maintenance process in terms of the quality, time, and resources

LC4.9 - Safety initiatives and designs and ensure the safe work environment

LC4.10 - Office TPM practices established via strong interdepartmental relationships

LC4.11- Extensive reliability analysis for the maintenance considering the economic levels and techniques of preventive and Predictive Maintenance (PdM) activities and equipment reliability

LC4.12 - Application of information systems to enhance the maintenance operations 


\begin{tabular}{|c|c|}
\hline $\begin{array}{l}\text { Leanness } \\
\text { attributes }\end{array}$ & Leanness Attributes \\
\hline \multirow{10}{*}{ 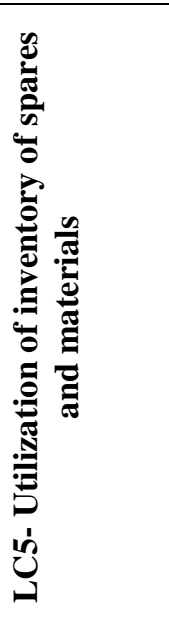 } & $\begin{array}{l}\text { L5.1 - Standardized practices for the issuing, staging, reordering, and reporting of the } \\
\text { departments and materials }\end{array}$ \\
\hline & L5.2 - IT-based communication \\
\hline & L5.3 - Distributed MRO storerooms placed in a centralized location \\
\hline & L5.4 - Encourage usage of standardized materials for common applications \\
\hline & L5.5 - Pull system Focus: Demand - driven inventory management \\
\hline & $\begin{array}{l}\text { L5.6 - Extend the preventive maintenance program to specific spares which need specific } \\
\text { attention in defined intervals }\end{array}$ \\
\hline & L5.7 - Constantly update the plants' inventory lists purging of the removed items \\
\hline & L5.8 - Tracked premature failures of equipment using store inventory or stock-outs \\
\hline & L5.9 - Designate the minimum and maximum levels for each spare part \\
\hline & $\begin{array}{l}\text { L5.10 - Generated part usage data through the CMMS can be used to organize the } \\
\text { storeroom }\end{array}$ \\
\hline \multirow{4}{*}{ 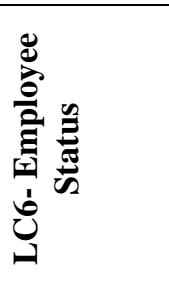 } & $\begin{array}{l}\text { L6.1 - Multi-skilled employees are formed through facilitating multiple skills training } \\
\text { programs for employees }\end{array}$ \\
\hline & $\begin{array}{l}\text { L6.2.- Self - directed, task-oriented action teams are formed through the multi-department } \\
\text { membership for maintenance activities }\end{array}$ \\
\hline & L6.3.- Encourages the Job rotation system \\
\hline & L6.4.- Flexible workforce formation adopts the new technologies \\
\hline \multirow{4}{*}{ 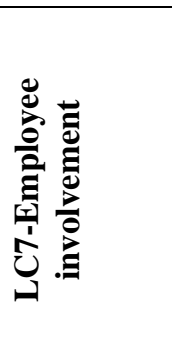 } & $\begin{array}{l}\text { L7.1.- Self-directed employees pursuing continuous improvements and performed work } \\
\text { with the value focus thinking }\end{array}$ \\
\hline & $\begin{array}{l}\text { L7.2.- Strong and cooperation was established via top-down communication (feedback } \\
\text { charts improvement measurements) }\end{array}$ \\
\hline & $\begin{array}{l}\text { L7.3.- Employee morale is uplifted through Provision of remuneration based on their } \\
\text { significant performance }\end{array}$ \\
\hline & $\begin{array}{l}\text { L7.4 - Employees were given the decision-making power and increased the level of } \\
\text { autonomy }\end{array}$ \\
\hline
\end{tabular}

Eventually, the leanness assessment model was formulated concentrating the expanded "leanness criteria" into 4 main "leanness enablers" (Figure 1).

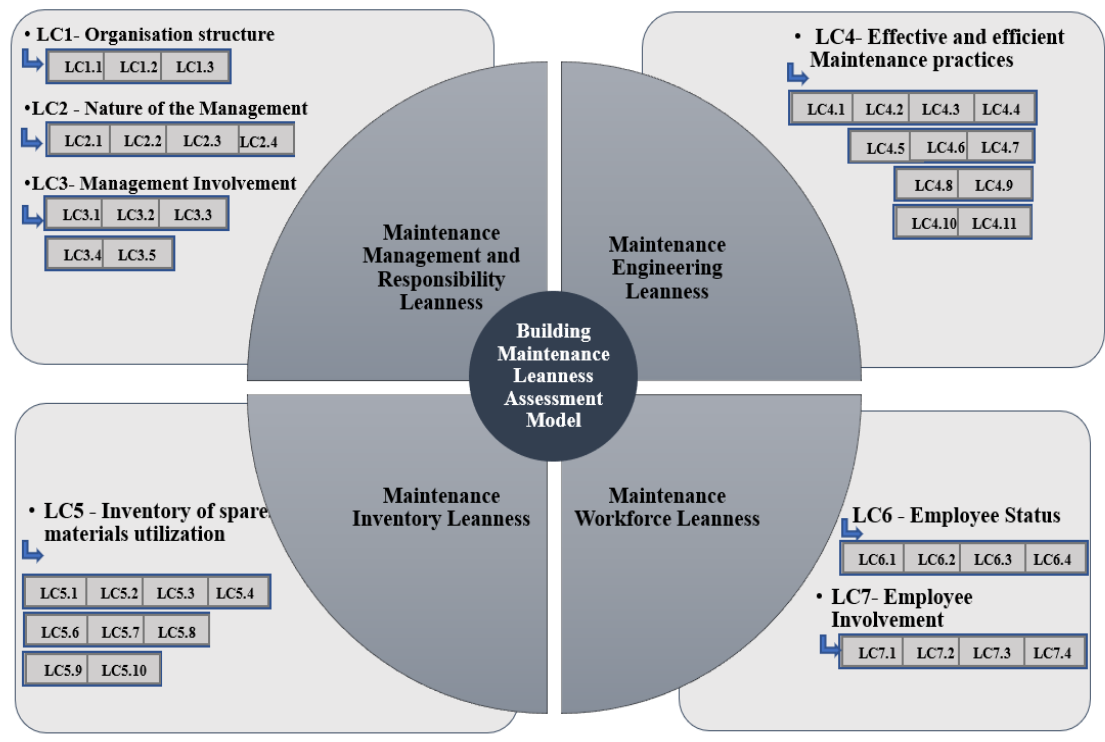

Figure 1: Leanness assessment model 


\section{RESEARCH METHODOLOGY}

The research design provides a clear and solid pathway or framework to answer the identified research problem (Saunders et al., 2009). Accordingly, the qualitative research approach deployed considering the nature of the research problem in which the focus is to assess the current maintenance practices by answering the "How" and "Why" type questions (Yin, 2018). Furthermore, it supported the researcher's intention of deriving valuable insights on research outcomes from in-depth discussions with the professionals who are actively involved in that field (Creswell , 2003). Driven by that intention, adopted case study research strategy can be justified as the study investigates the real-life phenomenon, a quality of leanness exists within the building maintenance practices occurred in the operation stage in which lack of leanness aspects account for increasing maintenance inefficiencies and risen maintenance-related expenses (Yin, 2018). As it facilitates the competitive advantage over the random sampling technique (Patton and Appelbaum, 2003), research deploys a non-probability sampling technique: snowball sampling where initial respondents were selected on probability and then the network of respondents was formed via information obtained from initial respondents (Acharya et al., 2013). Accordingly, three identical cases from the apparel industry buildings from the Sri Lankan context were selected expecting the literal replication logic (Yin, 2018). Further researcher purposefully considered the building units from apparel manufacturing industry as a case boundary, since the lean culture is rooted to a certain extent in the manufacturing domain (Wickramasinghe and Perera, 2016) and research outcome will be an aid to achieve the competitive edge in their operations. A total of 9 semi-structured interviews were conducted with managerial level respondents considering their involvement in maintenance-related decision-making and engagement in the maintenance workforce management. Detailed profiles of the interviews from selected cases were tabulated in Table 2.

Table 2: Profile of the interviewees

\begin{tabular}{|c|c|c|c|c|}
\hline Case & Code & Designation & Role & Experience \\
\hline \multirow[t]{3}{*}{$\begin{array}{c}\text { Case } \\
01\end{array}$} & C1R1 & $\begin{array}{l}\text { Engineering } \\
\text { Manager }\end{array}$ & $\begin{array}{l}\text { Undertakes informed decisions to maintain the } \\
\text { assigned plants with sustainable operation }\end{array}$ & 7 Years \\
\hline & C1R2 & $\begin{array}{l}\text { Premises } \\
\text { Engineer }\end{array}$ & $\begin{array}{l}\text { Responsible for the smooth operation of the } \\
\text { building services in the facility. }\end{array}$ & 5 Years \\
\hline & C1R3 & $\begin{array}{l}\text { General } \\
\text { Manager }\end{array}$ & $\begin{array}{l}\text { Liable for making informed decisions on the } \\
\text { maintenance of utility services and machinery }\end{array}$ & 14 Years \\
\hline \multirow[t]{3}{*}{$\begin{array}{c}\text { Case } \\
02\end{array}$} & C2R1 & $\begin{array}{l}\text { Factory } \\
\text { Engineer }\end{array}$ & $\begin{array}{l}\text { Responsible for the smooth operation of the Hard } \\
\text { FM services }\end{array}$ & 4 Years \\
\hline & $\mathrm{C} 2 \mathrm{R} 2$ & $\begin{array}{l}\text { Factory } \\
\text { Engineer }\end{array}$ & $\begin{array}{l}\text { Responsible for the smooth operation of the Hard } \\
\text { FM services. }\end{array}$ & 8 Years \\
\hline & C2R3 & $\begin{array}{l}\text { Maintenance } \\
\text { Engineer }\end{array}$ & Responsible for the maintenance of utility services & 2 Years \\
\hline \multirow[t]{3}{*}{$\begin{array}{c}\text { Case } \\
03\end{array}$} & C3R1 & $\begin{array}{l}\text { Senior } \\
\text { Executive - } \\
\text { Engineering }\end{array}$ & $\begin{array}{l}\text { Responsible for handling maintenance projects, } \\
\text { energy, and sustainability projects. }\end{array}$ & 6 Years \\
\hline & C3R2 & $\begin{array}{l}\text { Senior } \\
\text { Executive - } \\
\text { Engineering }\end{array}$ & $\begin{array}{l}\text { Responsible for handling the maintenance projects } \\
\text { and the maintenance of the utility supply section. }\end{array}$ & 4 Years \\
\hline & C3R3 & $\begin{array}{l}\text { Assistant } \\
\text { Manager - } \\
\text { Engineering }\end{array}$ & $\begin{array}{l}\text { Responsible for the labour allocation in the PM } \\
\text { Program }\end{array}$ & 8 Years \\
\hline
\end{tabular}


Derived data were analysed using the code-based content analysis technique, which is a reflective process, that involves continuous actions of identifying, condensing meaning units, coding, and categorizing while revisiting the raw data to achieve the comprehensive analysis (Erlingsson and Brysiewicz, 2017). The marked similarities and dissimilarities of selected cases were interpreted using the cross-case synthesis and it facilitated the reader to assess the levels of leanness in building maintenance via argumentative interpretations.

\section{FINDINGS}

Based on empirical findings, the accomplishment of thirty-eight (38) attributes out of forty-two (42) leanness attributes were recorded as the highest score whereas accomplishment of twenty-five (25) leanness attributes was recorded as the lowest. Accordingly, highlights of case findings were presented in a detailed manner under the following key themes.

\subsection{MANAGEMENT AND RESPONSIBILITY LEANNESS}

Under this dimension, the highest number of attributes (12) were fulfilled by case 2, and the least number (10) was achieved by case 3 . Under "LC1- organization structure", the existing organizational structures of selected cases were established in a manner that supports minimizing the wastage commonly found in conventional vertical structures. As per respondent notion, the formation of teams within the existing structure and active collaboration of team members for decision making via "brainstorming sessions" has smoothened business operations. In case 2, "cross-functional teams" formulated including various levels of employees from various departments. Furthermore, respondents stressed the importance of information technology (IT) -based systems over manual operations to obtain a smooth informational flow while eliminating the potential time delays in communication. However, cases 1 and 3 have paid considerably less attention to visual displays of safety, quality, cost, delivery, and productivity data to the employees as a mechanism to easily trigger potential wastage.

Under "LC2- Nature of the Management" all the respondents oversee the manager as a supportive, responsible, and reactive figure away from his conventional role of directing. CIR3 emphasized the importance stating, "performance of the plant heavily lies on the nature of the manager". Furthermore, as highlighted in LC2.2, in all cases, the manager appeared as a self-motivated visionary personality that constantly motivates their team members via regular morning meetings, interacting with their employees and collecting their ideas for the betterment. In case 1, C2R1 stressed the three vital aspects of management: "leadership, process and people management". Further, he elaborated, "leadership will set up the vision and the mission, the process will set up the required guidelines to be followed(audits) and training we are giving required awareness to the employees". In LC2.4, compared to other cases, only case 2 equipped the management and employees with lean practices. Thus, from the researcher's point of view, management awareness on lean seemed to be a critical success factor for implementation in which ultimately highlighted through the highest leanness score.

Under "LC3- Management Involvement" management is actively involved with the development of standard work in collaboration with their teams based on employee feedback, "Gemba walks", Kaizen programs. Moreover, the horizontal flow of the value of the entire value stream is highly considered the belief, that different divisions 
(technical, quality, production) are highly interconnected. When it comes to the LC3.3, cases 1 and 2 are highly concerned with the development capability of their employees. C1R1 mentioned organization attempts on equipping the mechanics with mainly with technical skills whereas management with human skills, conceptual (Analytical skills) skills. Comparatively, case 2 deploys the specific lean application "Skill matrix" to address the skill gaps of the employees.C2R1 mentioned the employees are given a different type of training based on their employee level namely "technical training and management basis training". He further elaborated "technical training opportunities will be arranged based on the qualitative (Personal opinions, upcoming trends, and technological advances) and quantitative factors (MTTR, downtime), etc". Apart from that, case 2 set a strong focus on giving knowledge of lean for all levels of employees. Furthermore, in cases 1 and 2 adherence to the lean tools: Root cause analysis, Pareto tools, Gemba walks have been used to enhance the versatility of the decisions. It is clearly highlighted in the C2R3's statement “... if we found strong deviations from the set target or goals, we go ahead with the five day - Kaizen events to share knowledge with the high performing units in the group and come up with the feasible solutions for the deviations."

\subsection{MAINTENANCE ENGINEERING LEANNESS}

Under this dimension, the highest number of attributes (11) were achieved by case 2 and the least number (6) was by case 3. Under "LC4-Effective and efficient maintenance practices" Cases 1 and 2 adhered with the lean maintenance tool, TPM whereas case 3 abide by combined practices of preventive and predictive maintenance strategies. Under TPM they followed the two branches: Planned Maintenance (PM) and AM. Under PM, all cases concerned heavily on preventive maintenance aspects rather than going for advanced PdM strategies. Moving on to AM aspects, case 1 practices mainly for sewing machine operations compared to the building asset maintenance. Simultaneously, case 2 deploys a comprehensive AM program along with the yearly basis training and audits programs to assess the success. C2R3 stated, "operators were given with two time periods to the AM per day, and engineering team will collect those tags and put the data into a database (through excel) check the details on issues, who maintained likewise". However, all three cases were unable to address the "LC4.11- Extensive reliability analysis for the maintenance considering the economic levels and techniques of preventive and predictive maintenance activities, and equipment reliability". Moreover, all three cases deploy information systems to accelerate maintenance operations. In case 1, BMS, a softwarebased daily preventive monitoring system and work order management systems are established. Gathered data through the aforesaid systems, are effectively utilized for the informed maintenance decision-making. With the aid of data management guides the employees to undertake the PDCA, RCA to come up with the actual causes for problems.

Accordingly, C1R1 mentioned, "reducing the maintenance services that they have contracted with suppliers and enhance the skills of the in-house teams undertake the maintenance activities as a result, they were able to achieve $80 \%$ of in-house maintenance PM data has been contributed a lot". Moreover, case 3 paid less for the initiation of comprehensive and detailed analysis to systematically trigger the problems. It was highlighted those Lean tools such as 5 WHYs, RCA, Gemba walks, honour cycles, fiveday kaizen programs are used by the case 1 and 2 in comparison to case 3 where the excelbased data sheet facilitated to come up with the informed decisions. Apart from that, all the cases are set to focus on continual evaluation and improvement of the maintenance activities in terms of quality, time, and resources. Both cases 1 and 2 deployed the PDCA 
process as a continual evaluation tool for maintenance activities while case 3 deployed the separate continuous monitoring and evaluation team for maintenance improvements.

\subsection{MAINTENANCE INVENTORY LEANNESS}

Under this dimension, the highest number of attributes (8) were fulfilled by case 2 and the least number (6) was by case 3. Under the "LC5- Utilization of inventory of spares and materials", demand driven inventory management systems were maintained by all the cases. They have paid significant attention to the impact on business operations. C1R2 stated, "we have categorized ( $A, B, C, D)$ the based on their risk and criticality". Further, he elaborated," high risk high critical items are maintained through reorder level, compared to its high-risk low critical items are maintained when the requirement emerged". Apart from that, few of the best practices that organizations followed are derived: centralization of all the spare parts within the factory units in the cluster, procure the similar models that consume the similar spare parts and local spare parts usage. Yet, strong deviations were identified within the existing practices concerning the leanness attributes (LC5.8 and LC5.9). The constant update of the plants' inventory lists purging of the removed items, tracked the premature failures of equipment using inventory consumption are identified as untouched areas, and has the potential of curtailing the wastage. However, lack of adherence can be observed in all cases except case 1, where the maintenance storerooms are utilized using the data generated through CMMS.

\subsection{MAINTENANCE WORKFORCE LEANNESS}

Under this dimension, all the attributes (08) were fulfilled via case 2 and the least number (3) was by case 3 . Comparatively, case 2 contributed significantly to employee development, considering the "non- utilized employee skill" as a waste to the organization. Under "LC6- Employee status" case 1 and 2 have paid concern on forming the multi-skilled workforce. In case 1, C1R3 mentioned, "it is done through the comprehensive plan which maps the employee actual potential, company expectations from the employee, provision of both theory and practical gaps." Furthermore, strategies like "Job rotation" were highlighted in which a good opportunity for case 3 enhances their existing practices. In case 1 CIR1, CIR2 highlighted "succession planning" as a strategy of employee development.

Under "LC7- Employee involvement", in all cases, employees are encouraged to pursue continuous improvement efforts and performed the work with value focus thinking. More often management encourages the continuous improvement culture. As stated by C1R2 "kaizen ideas were linked with employees, KPI (innovation per year) and employees enthusiastically engage in that event". Moreover, C2R1 mentioned, "regular meeting, quiz, competitions, auditing were organized to boost their skills as a well as the morale". Comparatively, case 3 has taken fewer efforts on forming the self-directed employees as there is a lack of organized events to grab their active cooperation. Furthermore, in cases 1 and 2 a higher employee involvement was observable compared to case 3 due to the reward-based performance evaluation system where employees were induced by monetary incentives. C3R2 mentioned, "we already developed the evaluations sheets forms, but has not seemed to be much strong motivate as it lacks the parts of giving them awards or incentives" which can be identified as a lagging factor of motivating their employees for better performance. However, all three organizations focused on establishing strong top-down communication mostly via regular morning meetings. Apart 
from that, both cases 2 and 3 highlighted the feedback sessions as an improvement measurement. Furthermore, in all cases, employees were given autonomy to perform their duties mainly based on their skill levels under the direct supervision of immediate management.

\section{DISCUSSION}

Findings disclosed in all cases, team-based flatter structures enhanced better communication, induced empowerment, less bureaucracy new development opportunities (Powell, 2002). Yet, findings raised the lagging point in terms of enhancing the communication via charts that depicts safety, quality, cost, delivery, and productivity data to the employees. As a favourable solution to it, storyboarding which is a simple graphical panel that enhances information access can be recommended (Davies and Greenough, 2001). Empirical findings further pointed out the emerging need of promoting the lean concepts via training sessions among managerial level workers as they are the driving force in achieving the higher degree of leanness (Smith and Hawkins, 2004). When it comes to the maintenance engineering leanness dimension, the importance of engaging with RCM concepts and tools was raised to effectively address the reliability aspect of maintenance in the local context (Johannesson et al., 2013). Furthermore, identified lagging points in adherence to AM can be addressed by enhancing the operators' skill, giving operators ownership to perform the machine cleaning, simple minor routine adjustments, and maintenance (Yile et al., 2008). Away from the positive efforts taken by practitioners to enhance the maintenance workforce leanness, the "cross-functional team set up" derived through case 2 appeared to curtail potential information wastage while allowing room for potential improvements in line with the horizontal value stream. It is formed the self-directed, task-oriented action teams via through the multi-department membership for maintenance activities that are significantly contributed to develop the employees set up. Yet, from the researcher's point of view, it can be a real eye-opener for the industry to adhere in to. Furthermore, the empirical investigation proved the provision of adequate information, skills and motivation, and power that enable favourable obtaining of employee involvement (Benson et al., 2004). Following that fact, findings encouraged for the reward-based performance evaluation system where employees induced by monetary incentives (Zatzick and Iverson, 2006). Moreover, quizzes, competitions to enhance the employee's performance also act as the motivating factors to induce their active engagement in local context.

\section{CONCLUSIONS}

At a time when Lean Maintenance is still a relatively new concept in Sri Lanka, the study will draw the readers' attention to embedding those principles to enhance maintenance operations. The overall study portraits the application of the information template to assess the degree of leanness that exists within the building maintenance. Based on the extensive literature analysis on "Lean Maintenance" and "Lean Thinking maintenance", forty-two (42) leanness attributes were derived and tested with three identical cases in the apparel industry. Empirical findings showcased the favourable adherence to lean practices in the local context, stressing the potential rooms for improvements. Accordingly, the importance of extensive reliability analysis for the maintenance considering the economic levels and techniques of preventive and predictive maintenance activities and equipment reliability, lack of incorporation of the planned maintenance 
program with inventory management aspects outcome with existing gaps in selected all cases. It is recommended to implement those actions on extending the planned maintenance programs touching the reliability aspects and interlink inventory management with PM programs of the facility. Furthermore, it will be a versatile effort to conduct the lean awareness sessions, promote multi-skill training programs to all levels to grab their active involvement in maintenance operations. Value focus mindset of the employees can be distinguished as a dominant factor that drives to acquire a higher degree of leanness in maintenance environments in Sri Lankan context.

\section{REFERENCES}

Abreu, A., Calado, J.and Requeijo, J., 2016. Buildings lean maintenance implementation model. Open Engineering, 6(1), pp. 397-406.

Acharya, A.S., Prakash, A., Saxena, P. and Nigam, A., 2013. Sampling: Why and how of it? Indian Journal of Medical Specialities, 4(2), pp. 330-333.

Alemi, M. and Akram, R., 2013. Measuring the leanness of manufacturing systems by using fuzzy topsis: A case study of the 'Parizan Sanat' company. South African Journal of Industrial Engineering, 24(3), pp. 166-174.

Ali, A.S., Chua, S.J. and Ali, D. B., 2016. Issues and challenges faced by government office buildings in performing maintenance work. Jurnal Teknologi, 78(11), pp. 11-23.

Baluch, N., Abdullah, C.S. and Mohtar, S., 2012. TPM and lean maintenance - A critical review. Interdisciplinary Journal of Contemporary Research In Business, 4, pp. 850-857.

Benson, G.S., Finegold, D. and Mohrman, S., 2004. You paid for the skills, now keep them: Tuitionreimbursement and voluntary turnover. Academy of Management Journal, 47(3), pp. 315-331.

Chan, D.M., Chan, A. and Choi, T.N., 2009. Implementing the mandatory building inspection scheme (MBIS) in Hong Kong - an exploratory study. (p. 41). Adelaide: University of South Australia..

Clarke, G., Mulryan, G. and Liggan, P., 2010. Lean maintenance - A risk based approach. Pharmaceutical Engineering, 30(5), pp. 1-6.

Cocca, P., Marciano, F., Alberti, M. and Schiavin, D., 2019. Leanness measurement methods in manufacturing organisations: A systematic review. International Journal of Production Research, 57(15), pp. 5103-5118.

Madureira, S., Flores-Colen, I., de Brito, J. and Pereira, C., 2017. Maintenance planning of facades in current buildings. Construction and building materials, 147, pp.790-802.

Creswell, J.W., 2003. Research design: Qualitative, quantitative and mixed methods approaches. $3^{\text {rd }}$ ed. Thousand Oaks, CA: SAGE.

Davies, C. and Greenough, R.M., 2001. Maintenance survey - Identification of lean thinking within Maintenance.Cardiff:UK, $17^{\text {th }}$ National conference on manufacturing research., pp. 37-42.

Erlingsson, C. and Brysiewicz, P., 2017. A hands-on guide to doing content analysis. African Journal of Emergency Medicine, 7, pp. 93-99.

Gupta, S., Gupta , P. and Parida , A., 2019. Modeling lean maintenance metric using incidence matrix approach. International Journal of System Assurance Engineering Management, 8, pp.799-816.

Hallam, C., 2003. Lean enterprise self-assessment as a leading indicator for accelerating transformation in the aerospace industry. Cambridge: Massachusetts Institute of Technology.

Johannesson, P., Bergman, B., Svensson, T. and Arvidsson, M., 2013. A robustness approach to reliability, Quality and Reliability Engineering Journal, 29, pp. 17-32.

Kim, W. and Katipamula, S., 2018. A review of fault detection and diagnostics methods for building systems. Science and Technology for the Built Environment ,24, pp. 3-21.

Lahiri, R.N., Sinha , A. and Chowdhury, S., 2008. Importance of strategic maintenance management for Indian utility industry. Pittsburgh: IEEE.

Lateef, O.A., Khamidi, M.F. and Idrus, A., 2010. Building maintenance management in a Malaysian university campuses: A case study. Australasian Journal of Construction Economics and Building, 10(1-2), pp. 76-89. 
Liker, J.K., 2003. The Toyota new way. New York: McGrew-Hill.

Mostafa, S., Lee, S.H., Dumrak, J. and Chileshe, N., 2015. Lean thinking for a maintenance process. Production and Manufacturing Research: An Open Access Journal, 3(1), pp. 236-272.

Narayanamurthy, G. and Gurumurthy, A., 2016. Leanness assessment: A literature review. International Journal of Operations and Production Management, 36(10), pp. 1115-1160.

Patton, E. and Appelbaum, S., 2003. The case for case studies in management research. Management Research News, 26(5), pp. 60-71.

Poppendieck, M., 2002. Principles of lean thinking. Minnesota, Poppendieck. [Online] Available from: https://www.okyanusbilgiambari.com/bilgiambari/Yalin/Yalin.Fabrika/Leanthinking.Software.pdf [Accessed 18 April 2021].

Powell, L., 2002. Shedding a tier: Flattening organisational structures and employee empowerment. The International Journal of Eductaional Management, 16(1), pp. 54-59.

Puķīte, I. and Geipele, I., 2017. Different approaches to building management and maintenance meaning explanation. Procedia Engineering, 172, pp. 905-912.

Salata, F., de lieto Vollaro, A., de lieto Vollaro, R. and Davoli, M., 2014. Plant reliability in hospital facilities. Energy Procedia, 45, pp. 1195-1204.

Saunders, M.N., Lewis , P. and Thornhill, A., 2009. Research methods for business. $5^{\text {th }}$ ed. Harlow, England: Prentice Hall.

Shou, W., Wang, J., Wu, P. and Wang, X., 2019. Value adding and non-value adding activities in turnaround maintenance process: classification, validation, and benefits. Production Planning and Control, 31(1), pp. 60-77.

Singh, B., Garg, S.K. and Sharma, S.K., 2010. Development of index for measuring leanness: study of an Indian auto component industry. Measuring Business Excellence, 14(2), pp. 46-53.

Smith, R. and Hawkins, B., 2004. Lean maintenance: Reduce costs, improve quality, and increase market share. Burlington: Elsevier.

Thürer, M., Tomašević, I. and Stevenson, M., 2016. On the meaning of 'waste': Review and definition.. Production Planning and Control, 28(3), pp. 244-255.

Urban, W., 2015. The lean management maturity self-assessment tool based on organizational culture diagnosis. Procedia - Social and Behavioral Sciences, 213, pp. 728-733.

Verma, A.K. and Ghadmode, A., 2004. An integrated lean implementation model for fleet repair and maintenance. Naval Engineers Journal, 116, pp. 79-90.

Wan, H.D. and Chen , F.F., 2009. Decision support for lean practitioners: A web-based adaptive assessment.. Computers in Industry, 60, pp. 277-283.

Wickramasinghe, G.L. and Perera, A., 2016. Effect of total productive maintenance practices on manufacturing performance.Investigation of textile and apparel manufacturing firms. Journal of Manufacturing Teachnology Manangement, 27(5), pp. 713-729.

Womack, J.P. and Jones, D.T., 2003. Lean thinking - banish waste and create wealth in your corporation. London: Simon and Schuster UK Ltd..

Yile, L., Hang , X.X. and Lei , Z., 2008. Lean maintenance framework and its application in clutch maintenance. Taipei,Taiwan, IEEE, pp. 19-21.

Yin, R.K., 2018. Case study research and applications: design and methods. India: SAGE Publications, Inc.

Zatzick, C.D. and Iverson, R.D., 2006. High-involvement management and workforce reduction: competitive advantage or disadvantage?. Academy of Management Journal, 49(5), pp. 999-1015. 